\section{RCD))}

O corpo a corpo feminista nas ruas e nas telas

latino-americanas

\author{
The feminist embodied struggles on the Latin American
}

streets and screens

\title{
Geisa Rodrigues ${ }^{1}$
}

\begin{abstract}
Resumo: No cenário atual do retorno da potência das lutas e reivindicações feministas e eclosão das novas tecnologias e redes, diversos materiais audiovisuais têm sido produzidos e difundidos tanto para efeito de registro, como disseminação das manifestações nas ruas. Esta produção audiovisual tem como característica um redimensionamento do papel político do corpo da mulher, em que a exposição e a performance promovem uma manipulação produtiva de sua potência política. Partindo da hipótese de que tais materiais ensaiam um olhar político que se aproxima dos pressupostos caros a uma perspectiva pós-estruturalista de enfrentamento político, estabelecendo também vínculos com o feminismo decolonial e o feminismo interseccional, no presente artigo propomos uma análise articulada a tais pressupostos teóricos, para evidenciar de que forma os encontros dos corpos nas ruas e nas telas, por meio de tais produções podem se retroalimentar, apresentando uma alternativa eficaz de ocupação e proliferação das pautas políticas femininas por meio do audiovisual.
\end{abstract}

Palavras-chave: Manifestações de rua. Feminismo decolonial. Audiovisual. Performance.

\begin{abstract}
In the current scene of the return of the power of feminist struggles and claims, and the emergence of new Technologies and networks, many audiovisual materials have been produced and disseminated both for the purpose of registration and dissemination of street demonstrations. This audiovisual production is characterized by a new political role of the woman's body, in which exposure and performance promote a productive use of its political power. Based on the hypothesis that such materials rehearse a political perspective that approaches the presuppositions of a post-structuralist perspective of political confrontation, also establishing links with decolonial feminism and intersectional feminism, in this article we propose an analysis articulated to such theoretical assumptions, to show how the encounters of bodies in the streets and on the screens, through such productions, can feed back, presenting an effective alternative for occupation and proliferation of female political agendas through the audiovisual.
\end{abstract}

Keywords: Street demonstrations. Decolonial feminism. Intersectional feminism. Audiovisual. Performance.

\section{Introdução}

Nas duas últimas décadas, assistimos a uma intensificação das lutas e reivindicações feministas, ao ponto de diversas autoras classificarem o momento como uma "quarta onda feminista"2. Isso se evidenciou também no contexto

\footnotetext{
1 Doutora em Letras pela PUC-Rio e mestre em Comunicação pela Universidade Federal Fluminense (UFF). É professora do curso de Comunicação Social da UFF.

2 Utilizamos o termo, mas ressaltamos o caráter problemático da definição, visto que as classificações do movimento feminista em ondas pressupõem um movimento concebido a partir de uma perspectiva eurocêntrica. Entretanto, isto evidencia o fato de a luta das mulheres estar emergindo como um dos principais eixos de articulação e reivindicação política nas últimas décadas. Há que se considerar também que o termo "quarta onda" muitas vezes é usado exatamente para caracterizar um formato mais abrangente. Cecília Palmeiro, fundadora do movimento Ni una a menos, por exemplo, em entrevista à revista Cult, diz que a quarta onda feminista é, tipicamente, latino-americana.
} 
Latino-americano, sob influência tanto do advento das novas tecnologias de informação e comunicação como pela urgência de demandas latentes ante aos avanços de movimentos e políticas conservadoras. A relação entre as tecnologias de comunicação e o ativismo político colocaram o campo da comunicação em evidência tanto no meio acadêmico como no campo das disputas políticas, mesmo entre as parcelas conservadoras. Podemos afirmar que, sobretudo a partir de 2015, com a chamada "primavera feminista" (HOLLANDA et al., 2018; ESCOSTEGUY, 2020), adentramos um momento de retorno e efervescência nas investigações e debates pautados nas questões de gênero.

Escosteguy classifica este período entendendo-o como propulsor de um quarto impulso de estudos feministas no campo da comunicação ${ }^{3}$, caracterizado por "grandes manifestações feministas [...] e o horizonte aberto pela explosão dos feminismos, impulsionada pelas novas mídias digitais e por movimentos sociais negros, de favelas e de diversidade sexual." (ESCOSTEGUY, 2020, p. 110). Apesar de corroborarmos com esta classificação, convém ponderarmos que, de fato, as tecnologias e as redes sociais auxiliaram sensivelmente na proliferação da diversidade de ideias e pautas políticas das lutas feministas contemporâneas, mas é importante pensarmos nesta eclosão na última década não apenas como um efeito do acesso mais facilitado e "democrático" à produção proliferação de vozes proporcionado pelas novas tecnologias, mas de uma combinação de fatores, entre eles a herança dos debates e conquistas anteriores, bem como a conjuntura política que deu origem às manifestações eclodidas mundialmente na última década, sobretudo como reações aos efeitos de um formato de capitalismo tardio, que intensificou as desigualdades ao longo do tempo, visto que na ponta mais fraca permaneceram as intersecções de gênero e de raça, subjugadas há séculos. 0 que a autora intitula de "explosão dos feminismos" se caracteriza, principalmente, pela eclosão de novas pautas, novos grupos e coletivos ganhando as redes e as ruas. Apesar de termos alguns exemplos de movimentos feministas que abraçaram causas diversas no passado, trata-se agora de uma outra dimensão para os protestos e reivindicações nascidos sob uma nova lógica de atuação e reivindicação políticas, que tentaremos elucidar mais à frente.

\footnotetext{
${ }^{3}$ A autora observa as transformações que a relação entre o campo da comunicação e o dos estudos de gênero sofreram, entre 1970 e 2015, apontando 4 impulsos: a arrancada inaugural (19801990), com a conceituação sistemática da categoria mulher; o segundo impulso (1990), com o uso do termo gênero, mas ainda pouco aprofundado, e o terceiro (2000-2015), com a crítica ao pós-feminismo e a fase pós 2015, acima tratada.
} 
A relação que esta geração estabelece com os produtos e meios de comunicação vem se tornando tema latente dos debates e das pesquisas dedicadas às questões de gênero. Se na primeira década do século XXI grande parte ainda se dedicava à produção de sentidos e às representações nas mídias tradicionais (ECOSTEGUY, 2021), a partir de 2015 cresce o interesse pelos produtos e formas de comunicação em redes e aplicativos via internet. Neste período, observamos também a proliferação de coletivos de comunicação alternativa, bem como da produção advinda de dentro dos movimentos e grupos. Este artigo nasce do desejo de investigarmos um material que vem sendo difundido nas redes, a saber, vídeos produzidos e difundidos por coletivos e associações de mulheres na América-Latina, tanto para efeito de registro, como disseminação das lutas travadas nas ruas e no cotidiano dessas hermanas. Intentamos verificar, por meio da análise dos materiais selecionados, como as pautas femininas contemporâneas, desde o sul, se interseccionam no discurso audiovisual desses produtos de comunicação, bem como por meio deles pode se reconfigurar o papel político do corpo da mulher. Partimos da hipótese de que a exposição e a performance colocadas em cena nos materiais analisados promovem uma manipulação produtiva da potência política dos corpos femininos a partir de uma perspectiva que visa combater os efeitos sociais e culturais da colonização da América Latina. Outra hipótese levantada é a de que tais materiais talvez estejam inaugurando um estilo midiativista de produção de audiovisual de divulgação, direcionado para enfrentamentos, estratégias e articulações condizentes com o atual contexto político.

A pesquisa e análise proposta no presente artigo se baseia em alguns dos referenciais teóricos do pensamento feminista pós-estruturalista, do feminismo interseccional e do feminismo decolonial, não apenas por afinidade com a pesquisa que vimos desenvolvendo dentro do curso de Comunicação Social da UFF, mas por entendermos serem essas as linhas de pensamento que mais se conectam com os formatos políticos de reivindicação contemporâneos observados. Também serão articulados no texto e na análise o trabalho de teóricos vinculados aos Estudos Culturais e a perspectiva teórico-metodológica da Análise do Discurso, de forma a expor a potência política do audiovisual como elo articulador de afetos nos movimentos de mulheres contemporâneos. Nesses formatos mais recentes de interlocução política por meio de produtos de comunicação audiovisual, as muIheres e suas múltiplas pautas assumem uma dimensão protagonista do olhar, por meio de sequências de imagens em que há uma valorização dos afetos e dos 
corpos femininos postos em cena. Identificarmos nestes materiais uma potencialidade latente de transformação política e, ao mesmo tempo, uma capacidade de entrecruzar pautas e reivindicações.

A exemplo do que sugere Nancy Fraser (2006), para além do reconhecimento das diferenças, trata-se de trabalhar transformações, no sentido de desestabilizá-las, criando possibilidades de "futuros reagrupamentos". Há de se considerar também a capacidade de disseminação de tais vídeos. Trata-se de um material divulgado em encontros, palestras, eventos políticos, redes sociais etc. e, portanto, com alto potencial de disseminação. Outro aspecto observado é a influência deste tipo de registro sobre os materiais audiovisuais da mídia tradicional. Guardadas as devidas ressalvas referentes aos interesses econômicos e políticos dos grandes conglomerados de comunicação, de alguma forma, essas imagens, ao serem inseridas em meio à grade jornalística, permitem que se abram frestas, trazendo os telespectadores e ouvintes para um "lócus fraturado" (LUGONES, 2014) dos corpos em cena. Mirando no exemplo da leitura de Walter Mignolo sobre a obra de Glória Anzaldúa, Maria Lugones entende que uma chave para descolonizar o poder seria buscarmos lócus fraturados de resistência, pontos de partida para uma coalizão. O conceito é proposto pela autora para pensar capacidade de resistência mesmo em espaços em que prevalece ainda a lógica do sistema colonial.

Conforme a colonialidade infiltra cada aspecto da vida pela circulação do poder nos níveis do corpo, do trabalho, da lei, da imposição de tributos, da introdução da propriedade e da expropriação da terra, sua lógica e eficácia são enfrentadas por diferentes pessoas palpáveis cujos corpos, entes relacionais e relações com o mundo espiritual não seguem a lógica do capital. A lógica que seguem não é consentida pela lógica do poder. O movimento desses corpos e relações não se repete a si próprio. Não se torna estático e fossilizado. Tudo e todos/as continuam respondendo ao poder e na maior parte do tempo respondem sem ceder - o que não quer dizer na forma de desafio aberto, mesmo que às vezes seja em desafio aberto - de maneiras que podem ou não ser benéficas para o capital, mas que não são parte de sua lógica. A partir do lócus fraturado, o movimento consegue manter modos criativos de reflexão, comportamento e relacionamento que são antitéticos à lógica do capital (LUGONES, 2014, p. 948).

Esse lócus se instaura como marginal na medida em que reage à lógica do capital a partir de existências femininas que não se encaixam na colonialidade do poder e a desafiam. Neste sentido, a análise proposta busca explicitar de que 
forma os produtos audiovisuais reagem e resistem em sua forma estética, funcionando como condutores e propulsores destas existências.

A investigação proposta se restringe ao material produzido na América Latina a partir de 2015, de forma a contemplar a perspectiva política de abordagem decolonial feminina nas lutas latino-americanas. Para ilustrar as reflexões levantadas, selecionamos especificamente dois vídeos "promocionais" ${ }^{4}$ para uma análise mais detalhada: 1) Marcha Mundo de Mulheres por Direitos, do Portal Catarinas, Brasil, 2017; 2) Convocatório para a greve mundial feminista, da Coordinadora Feminista 8M (CVM), Chile, 2021. O primeiro vídeo traz registros realizados em Santa Catarina, em 2017; o segundo é um vídeo feito pela Coordinadora 8M chilena convocando as mulheres para ocuparem as ruas no 8 de março de 2021. A escolha se deve ao fato de se diferenciarem em termos de linguagens estéticas, mas terem uma série de pontos em comum em termos do formato de reivindicações e estratégias políticas de enfrentamento. Desta forma, a análise permite observarmos e escrutinarmos mais de uma possibilidade se tratando de experimentação estética e política de intervenção e, ao mesmo tempo, sugere uma coalização entre as lutas femininas latino-americanas. 0 escopo se limita a dois produtos audiovisuais, por consideramos que este formato nos permite analisar de forma mais aprofundada aspectos particulares e detalhados de cada um deles, bem como articular a análise ao pensamento político e teórico exposto. Desta forma, buscamos desenvolver uma abordagem que explore as discussões sobre os enfrentamentos políticos contemporâneos e a conjunção entre os movimentos nas ruas e a comunicação audiovisual.

\section{Que "feminino" é esse a que nos referimos?}

$\mathrm{Na}$ observação da articulação de elementos discursivos e estéticos nos vídeos em questão, um primeiro fator que chama a atenção é o esforço de afirmação e ao mesmo tempo ressignificação de elementos componentes das marcas de gênero. Principalmente se considerarmos que numa manifestação que se nomeia "feminina" ou "feminista", ou marcha de mulheres, na própria convocação e no título, o lugar "feminino", "mulher", está discursivamente e simbolicamente demarcado, ainda que as participações não necessariamente envolvam apenas

\footnotetext{
${ }^{4}$ Usamos aqui a classificação "promocionais" por serem feitos com o intuito de divulgar e disseminar as pautas políticas e não apenas para efeito de registro. São editados e transformados em produtos de "propaganda política" em prol de causas.
} 
corpos femininos cis. Isso ocorre porque as oposições à dominação masculina de alguma forma precisam ser demarcadas, na medida em que são manifestações relacionadas a decisões políticas referentes aos efeitos de relações de poder hierarquicamente instituídas por uma lógica branca, heteronormativa, masculina e elitista. Dessa forma, se essa demarcação de "gênero" já é a princípio estabelecida, convém indagar como os registros de manifestações que pretendem desnaturalizar e movimentar as normas e estruturas podem ser bem-sucedidas em sua proposta de ruptura política.

Stuart Hall, no texto "Que negro é esse na cultura negra?", em sua perspectiva culturalista e crítica, sugere um olhar mais atento e menos eufórico com relação aos riscos políticos que a assunção da identidade negra em produtos culturais poderia incorrer. Desta forma, insere uma questão que poderia aqui ser adaptada e reproduzida para o que confrontamos: "que tipo de momento é este para se colocar a questão da cultura popular negra?" (2011, p. 317). Basicamente, o que observa é que, em determinados momentos, foi preciso lançar mão de um "essencialismo estratégico" - aponta bell hooks 5 e Gayatri Spivak como autoras que souberam o pontuar muito bem -, mas questiona se a estética diaspórica de movimentos populares negros não estaria perdendo em potencialidade ao se inserir na essencialização naquele momento específico (1998, no caso). Dos aspectos adversos de que fala Hall, o que mais nos chama a atenção é a "profunda e ambivalente fascinação do pós-modernismo pelas diferenças sexuais, raciais, culturais e, sobretudo, étnicas" (2011, p. 319). A fascinação pelo "exótico" tão facilmente comercializável deixa evidente a fácil instrumentalização da diferença. No caso do Brasil e de nossos países vizinhos, é importante considerarmos a estrutura colonial, racista e sexista, que ainda tem fortes raízes em nossos hábitos, saberes e práticas culturais, sociais e políticas. A isto, se soma a combinação entre as atuais práticas neoliberais e a herança colonial que ainda assombra nossos produtos culturais, em particular por conta da participação efetiva dos meios de comunicação de massa no processo formador das identidades nacionais no século XX (MARTíN-BARBERO, 2015). Trazendo a pergunta para o contexto político contemporâneo e para as questões levantadas no presente artigo: em que momentos ou dadas situações será importante assumir as identidades demarcadas para o feminino? Não estariam também os próprios entrecruzamentos de classe, sexualidade, religião, entre outras intersecções possíveis sujeitos a esta dúvida?

\footnotetext{
${ }^{5}$ A autora adota a grafia do seu nome em letras minúsculas, como forma de dar destaque ao conteúdo do seu trabalho e não ao seu nome ou personalidade acadêmica.
} 
Nesta mesma linha de problematização, se insere o trabalho de teóricas pós-estruturalistas dedicadas ao tema das subjetividades contemporâneas. Destaca-se, neste sentido, o trabalho de Judith Butler (2003), ao observar que o feminismo tradicional precisa abandonar os vínculos à questão da representação, em todos os sentidos do termo. Neste aspecto estaria a base de uma abordagem universalista do gênero feminino, vista como algo negativo pela filósofa, principalmente por considerar que não é possível haver uma categoria definível, por conta das intersecções entre modalidades raciais, classistas, étnicas e sexuais de identidades. Butler entende que as práticas identitárias acabam virando armadilhas e sugere que seja substituído o conceito de gênero como metafísica da substância, para pensá-lo como performance, como processo em devir, visto que tudo que estivesse vinculado a identidades fixas, estaria também às formas jurídicas, às práticas discursivas normativas, às tecnologias do gênero etc.

Consideramos fundamental levantar essas reflexões, de forma que possamos elucidar as estratégias dos movimentos políticos contemporâneos, bem como investigar a eficácia das performances aqui observadas. A partir da análise dos vídeos em questão, por exemplo, evidenciamos que as manifestações têm escolhido uma estratégia próxima ao conceito de diferença sexual estabelecido pela teórica italiana Rosi Braidotti (2015), em que proclama as repetições como forma de contramemória. Ainda que essas nomenclaturas - bem como alguns símbolos trazidos pelos movimentos - remetam muitas vezes às feminilidades hegemônicas, esta proximidade revela também uma relação paradoxal: podemos revisitar lugares que a princípio foram essencializados para estrategicamente subvertê-los.

O uso do roxo e do vermelho, de flores, a exaltação do corpo da mulher e de elementos e símbolos associados ao feminismo, como veremos nas imagens dos vídeos analisadas a seguir, se aproxima da estratégia apontada por Braidotti (2015), que propõe um processo de reelaboração da lógica identitária dicotômica em que a cultura ocidental nos inseriu. Desta forma, quando nomeamos as ações em assembleia nas ruas como ações de mulheres, mas o fazemos para reivindicar, por exemplo, o direito à interrupção de uma gravidez indesejada, estamos criando uma ruptura com a ideia da maternidade como essência feminina. Na perspectiva Deleuziana adotada por Braidotti, o corpo feminino se apresenta como algo que não pode ser apreendido e representado. Essa complexidade confere uma potência política que parece estar sendo aproveitada nos vídeos aqui analisados. Uma mulher pode requerer o direito e as garantias a exercer a maternidade da melhor 
forma possível, assim como pode exigir o direito a não ser mãe, e a interromper uma gravidez, caso seja esse o seu desejo.

Retomando o tema da representação, é fundamental que os vídeos em questão não ignorem a complexidade que envolve o próprio regime de representação. A problematização do tema em Judith Butler pode nos guiar neste sentido. Há uma evidente divergência entre Butler e Braidotti, mas dentro da perspectiva de análise desenvolvida podem ser encontrados pontos de convergência na perspectiva pós-estruturalista de ambas, bastante profícuos para a investigação proposta. Em Problemas de gênero, Butler (2003) observa que a representação como afirmação não dá conta das questões políticas que envolvem o feminino, na medida em que só se estende ao que é reconhecido como sujeito (legitimado e normatizado). A autora assume que não há como evitarmos completamente o campo da representação, mas sugere "uma genealogia crítica de suas próprias práticas de legitimação". Anos depois o conceito de representação vai ser retomado pela autora, em Corpos em aliança e a política nas ruas. Agora, pensando no contexto da eclosão das manifestações de rua e das reivindicações sobre as questões de gênero mais contemporâneas:

Quando, muito tempo atrás, eu disse que o gênero é performativo, queria dizer que ele é um determinado tipo de representação, o que significa que uma pessoa não é primeiro o seu gênero e então, depois, decide como e quando representá-lo. A representação é parte de sua própria ontologia, é uma maneira de repensar o modo ontológico de gênero, e então importa como e quando e com que consequências essa representação se dá, porque tudo isso muda o gênero que alguém é (BUTLER, 2018, p. 68).

Essa concepção reafirma o papel performativo da linguagem do corpo, observado anteriormente por Butler, mas procura restituir os corpos de uma função que acabou se perdendo um pouco na ênfase à paródia e à performatividade linguística como marcos políticos de configuração de gênero. A sexualidade se define de forma performativa, mas isso não é completamente desvinculado dos efeitos das normas sobre os corpos. Seria interessante destacar aqui, neste sentido, a função da frase "O feminismo é o novo normal", que abre a locução da jornalista e ativista Antônia Pellegrino, num vídeo ativista brasileiro do Mídia Ninja sobre os movimentos e a luta feminista pós-2015, lançado em 2017.

Como isso se articula nas manifestações em questão? Somos afetados pelas nomeações que nos dão, em particular quando isso é determinado pelas 
instituições. As normas não só nos afetam como nos acompanham e, obviamente, vão acabar estruturando as nossas formas de resposta.

\begin{abstract}
Elas também nos "produzem", mas não no sentido de trazer à existência ou de determinar estritamente quem somos. Em vez disso, informam os modos vividos de corporificação que adquirimos com o tempo, e esses modos de corporificação podem se provar formas de contestar essas normas, até mesmo rompê-las (BUTLER, 2018, p. 37)
\end{abstract}

Como não há como evitarmos completamente o campo da representação e, como a autora sugere, é preciso fazer "uma genealogia crítica de suas próprias práticas de legitimação", para efeito de transformação de formas ativistas de manifestação, bem como de seus registros, nos perguntamos: como isso pode ser trabalhado nas ruas e reproduzido no audiovisual? Se pararmos para refletir que a mídia ao longo dos anos compôs o conjunto de práticas de legitimação, por exemplo, da erotização da juventude e da sacralização da maternidade, para pensar em extremos, o foco da filmagem nos textos dos cartazes, das faixas e dos corpos seminus pintados nos vídeos em questão podem ser pensados como forma de expor esse processo de maneira crítica. Frases como "Meu corpo, minhas regras" e "Demarcação, já" (inevitavelmente remetendo ao slogan "Diretas, já" dos anos 1980) se apropriam dos discursos de poder e ressignificam os termos. E se é a palavra de quem rege as relações de poder que legitima o que nossos corpos devem ser, é este mesmo artifício que vamos usar para nos posicionar. A potência destes filmes reside exatamente na problematização do próprio regime de representação que a mídia hegemônica nos impôs ao longo dos anos, visto tratar-se de um olhar completamente pautado na lógica hegemônica masculina, branca e heteronormativa. O protagonismo conferido aos corpos femininos nestes materiais rompe com as narrativas tradicionais e implode os lugares antes reservados aos corpos femininos. Isso fica evidente, tanto nos vídeos analisados quando os rostos e corpos de diferentes mulheres encaram o espectador, ou mesmo em diversos outros exemplos de vídeos do período, como quando a câmera filma o abraço coletivo de milhares de mulheres argentinas envoltas em lenços verdes, no vídeo argentino Hermanas (2018), durante os protestos a favor da legalização do aborto. 


\section{Deslocamentos, fronteiras e intersecções}

Outro aspecto que merece ser destacado e discutido antes de adentrarmos à análise dos vídeos é o caráter interseccional das reivindicações e lutas postas em cena. Para essa reflexão, convém resgatarmos o conceito de feminismo interseccional. O termo é frequentemente atribuído à teórica, ativista e feminista negra estadunidense Kemberlé Crenshaw, que de fato o sistematizou, em sua pesquisa sobre questões judiciais envolvendo reivindicações de mulheres negras. Porém, temos diversas pensadoras que se dedicaram à temática, sem nomeá-la dessa forma, como Patrícia Hill Collins, Audre Lorde, Angela Davis e, em particular, as pensadoras e ativistas brasileiras Lélia Gonzalez e Sueli Carneiro. O conceito tem sua base no feminismo negro, visto terem sido as feministas negras as primeiras a chamarem a atenção para questões que envolviam as intersecções de classe, raça e gênero, ignoradas durante anos por alguns dos principais movimentos feministas. O feminismo interseccional, na metodologia sugerida por Crenshaw, deve abarcar diversos entrecruzamentos de reivindicações:

A interseccionalidade é uma conceituação do problema que busca
capturar as consequências estruturais e dinâmicas da interação
entre dois ou mais eixos da subordinação. Ela trata especificamen-
te da forma pela qual o racismo, o patriarcalismo, a opressão de
classe e outros sistemas discriminatórios criam desigualdades
básicas que estruturam as posições relativas de mulheres, raças,
etnias, classes e outras. Além disso, a interseccionalidade trata da
forma como ações e políticas específicas geram opressões que
fluem ao longo de tais eixos, constituindo aspectos dinâmicos ou
ativos do desempoderamento (CRENSHAW, 2002, p. 177).

Essa abordagem vem sendo adaptada e articulada ao pensamento de autoras de outras vertentes e contextos em trabalhos que se debruçam sobre o campo da cultura e das representações. Carla Akotirene, por exemplo, aproxima o conceito de "amefricanidade" de Lélia Gonzalez (1998) e o pensamento decolonial de María Lugones (2014) desta perspectiva, visto que ambas, ao criticarem o projeto colonizador branco observando como as diversas opressões cruzadas, ajudaram a sustentar o "monopólio epistêmico ocidental" (AKOTIRENE, 2019). Flávia Rios e Alex Ratts (2010), no capítulo introdutório da biografia de Lélia Gonzalez, reiteram a afınidade do pensamento da autora com o pensamento interseccional. "Observamos isto quando ela associa o racismo, o sexismo e a exploração capitalista e 
quando articula as identidades de raça, gênero (este tratado à época como sexo) e classe" (2010, p. 3). Desta forma, a conexão entre os conceitos surge como uma potente reflexão sobre as políticas contemporâneas de enfrentamento. Como veremos mais à frente, na análise dos vídeos desenvolvida, pontuamos a ocorrência de um diálogo entre o resultado final desses materiais e essas categorias de articulação e reflexão política.

Do pensamento de Lélia Gonzalez, o conceito de amefricanidade, além de se aproximar do caráter interseccional da luta, sugere uma perspectiva que considera o entrecruzamento das questões minoritárias que atravessam América Latina e Caribe. A proposta seria unir os povos advindos da África e habitando as américas, para romper com a supremacia do pensamento branco e a ideia de uma superioridade europeia, ou melhor, um ponto de vista europeu, a partir do qual nossas nações (latino-americanas) teriam nascido, ainda que com o toque apimentado e mestiço de uma pretensa "democracia racial". Gonzalez foi uma das autoras que mais combateu a ideologia do Brasil como uma democracia racial, a que chama de "mito da democracia racial", desenvolvida por correntes intelectuais e políticas nas primeiras décadas do século XX e propagada até hoje em diversos espaços.

Por isso mesmo, a afirmação de que todos são iguais perante a lei assume um caráter nitidamente formalista em nossas sociedades. O racismo latino-americano é suficientemente sofisticado para manter negros e indígenas na condição de segmentos subordinados no interior das classes mais exploradas, graças a sua forma ideológica mais eficaz: a ideologia do branqueamento (GONZALEZ, 1998, p. 73).

O conceito de amefricanidade, além de reafırmar a importância do pensamento africano, insere uma lógica de libertação e combate aos efeitos do imperialismo centrada na voz e na percepção dos oprimidos e não nos opressores. Entendendo que não se faz revolução de "fora pra dentro", Gonzalez valoriza também saberes muitas vezes relegados a uma inferioridade, como a música, a ginga, a oralidade e os afetos advindos de África. Propõe também refutar a "exotização" e a mitificação da experiência africana, que acaba distanciando descendentes de sua ancestralidade e amenizando a violência da experiência da escravidão.

Somando-se a essa perspectiva, podemos citar aqui o pensamento de bell hooks no ensaio "Renegados, revolucionários: americanos nativos, afro-americanos e indígenas negros”, publicado na coletânea Olhares negros: raça e represen- 
tação (2019). Nesse ensaio, hooks sugere a conexão entre os primeiros africanos na América e os povos nativos, por meio da reverência à natureza, à vida e aos ancestrais. Havia um compartilhamento de costumes cuja potência pode ser resgatada na luta política contemporânea. Principalmente no que tange a conhecimentos ontológicos muito próximos, em que compartilhavam diversos sistemas de crenças. Não é à toa que usa como exemplo a experiência de povos africanos que aportaram na América antes de Colombo e não realizaram o desejo de "dominar e conquistar" como forma de confrontar o outro. Da mesma forma, os contatos travados entre nativos e negros não resultaram em conflitos e dominação, mas compartilhamento. Se procurarmos um paralelo brasileiro, os diversos cultos religiosos que mesclam entidades indígenas e africanas demonstram, mais que atos de resistência e sobrevivência (como muitas vezes se fez no sincretismo religioso), atos de comunhão na reverência à natureza. Hooks propõe laços sagrados de sangue e parentesco metafísico, uma sensibilidade compartilhada que poderia resgatar a potência da experiência desses povos. Partindo desses pressupostos, interpretamos a comunhão de mulheres de raças, povos e classes distintas que se reúnem nas manifestações, em sua potência transformadora. Convém observar, longe de se aproximarem de uma proposta feminista "universalista", as diferenças não são apagadas, mas, pelo contrário, reforçadas como pontes, surgem como elos de ligação para uma cosmovisão (hooks, 2019) de atuação política, em oposição a forças opressoras masculinas e capitalistas.

Um aspecto relevante e que aproxima os trabalhos de Gonzalez de hooks é a utilização de linguagem simples e abordagem direta de temas, ainda que envolvendo intensa produção e pesquisa intelectual. Isso sugere um cruzamento de fronteiras entre o pensamento acadêmico e as ruas, o cotidiano e os ativismos diários. Maria Lugones, em sua proposta de um pensamento marginal e feminismo decolonial, aciona a importância da feminista considerar a diferença colonial "resistindo ao seu próprio 'hábito epistemológico' de apagar a diferença colonial. Ao vê-la, ela vê o mundo renovado e então exige de si mesma largar seu encantamento como 'mulher', o universal, para começar a aprender sobre as outras que resistem à diferença colonial” (2014, p. 948). A autora propõe um pensamento de fronteira feminista, "onde a liminaridade da fronteira é um solo, um espaço, uma fronteira, para usar o temo de Gloria Anzaldúa, não apenas uma fenda, não uma repetição infınita de hierarquias dicotômicas entre espectros do humano desalmados" (LUGONES, 2014, p. 947). 
A proposta de Lugones, guardadas as devidas proporções de contextos de análise que as diferem, pode ser aproximada do conceito nomeado por Rosi Braidotti de feminismos nômades, inspirada no pensamento Deleuziano. Para além da concepção espacial e geográfica do termo, o nomadismo seria um tipo de consciência crítica que resiste a uma normatização, a lugares estabelecidos e formas fixas de comportamento (BRAIDOTTI, 1994, 2006). O sujeito nômade é visto como uma forma de resistência aos microfascismos a que somos submetidos, na lógica atual de poder. Isso é obtido principalmente por meio de experiências estéticas capazes de abandonar, subverter ou ressignificar categorias de representação, promover rupturas de formas discursivas canônicas e produzir novos formatos de inserção do desejo. Esta noção de subjetividades nômades para o feminino, da forma como é problematizada e ficcionalizada pela autora, também permite articular eixos de diferenciação, aproximando-se do que sugerem as perspectivas interseccionais de abordagem. Reiteramos que esta é, sem dúvida, uma característica marcante do material audiovisual midiativista, objeto do presente artigo, como veremos a seguir.

\section{Corpos em cena: análise dos vídeos}

\subsection{Vídeo 1 - Marcha Internacional Mundos de Mulheres, 2017, Brasil}

Este vídeo é uma realização do "Portal Catarinas: Jornalismo com perspectiva de gênero" e encontra-se disponibilizado para acesso livre. Trata-se de um material de registro do $13^{\circ}$ encontro Marcha Internacional Mundos de Mulheres, realizado em 2017, em Santa Catarina. O vídeo se inicia com o rosto da então vereadora Marielle Franco, participante do evento, gritando, "Primeiramente, fora Temer". Em seguida surge a imagem de uma ponte sobre as águas em que, ao som do vento, vemos as nuvens se movendo, remetendo à passagem de tempo e espaço, enquanto ouvimos a voz ativa das mulheres ao fundo. Podemos pensar que é como se essas vozes fossem o combustível para as nuvens e para o tempo, em deslocamento constante. As vozes ecoam "Filha da magia. Ela é do povo, não é da burguesia". Em seguida vemos uma profusão de imagens registradas durante a manifestação. Algumas estáticas, outras em movimento, além de pedaços de corpos, faixas, cartazes, imagens coletivas e individuais, enquanto ouvimos a música tema que acompanha uma boa parte do vídeo. Trata-se de uma música chamada "Cores de Aidê", 
que remete aos donos originais da terra e reconfigura a noção de pátria: "Índia, ó india. Teu cabelo negro se soma ao meu. Me acolhe pros braços teus".

O manifesto passa a ser registrado a partir da movimentação interna que vai desde os encontros às performances, aos atos de sacudir bandeiras, tocar um instrumento, se tocarem, se despirem, dançarem, gritarem, portar cartazes, pintar os corpos, exibir os corpos e o caminhar lado a lado. Mesmo que seja um caminhar para um destino final, há uma descontinuidade interna do caminhar que a câmera procura registrar. É importante destacar que o processo de montagem é feito com a consciência de que o papel do resultado estético final deve romper com a lógica da representação jornalística e documentarista tradicional, e trabaIhar mais o registro das sensações. A ocupação, no caso das imagens, se dá nesse campo das sensações, dos afetos e da experiência estética. Convém observar também que o trabalho do som aliado à montagem é fundamental no vídeo em questão. A abertura com a voz de uma mulher cantando enquanto assistimos a uma profusão de imagens internas da manifestação tem a função de dramatizar as cenas. A linguagem de videoclipe, além de funcionar de forma atraente, ressalta a diversidade de pautas em cena. Dos 4 min 26 s de filme, a montagem das imagens casadas à música de fundo ocupa cerca de dois minutos.

\section{Imagem 1 - Captura de tela do vídeo 1}

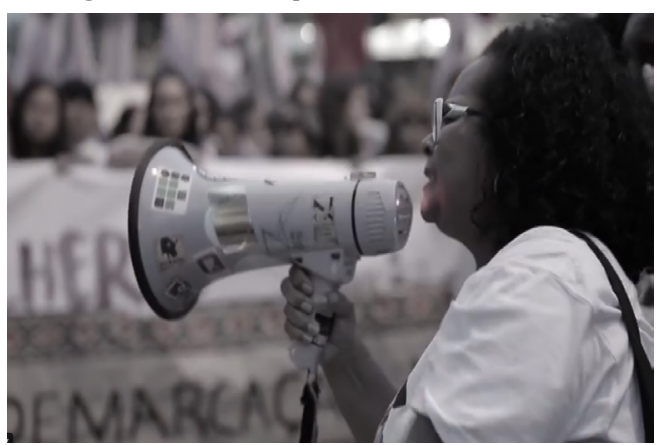

Fonte: Portal Catarinas (2017)

\section{Imagem 2 - Captura de tela do vídeo 1}

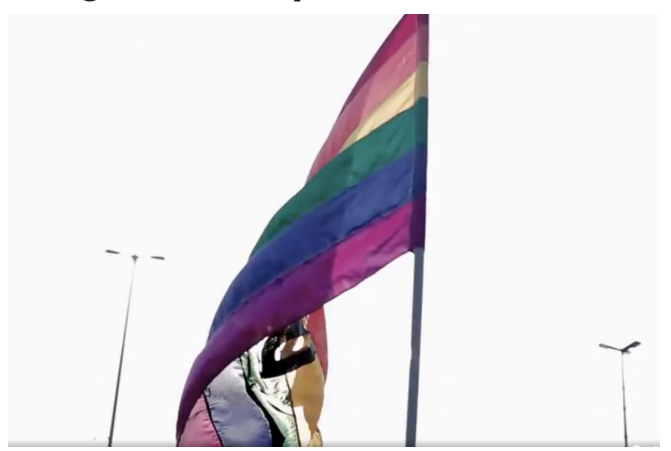

Fonte: Portal Catarinas (2017) 
Imagem 3 - Captura de tela do vídeo 1

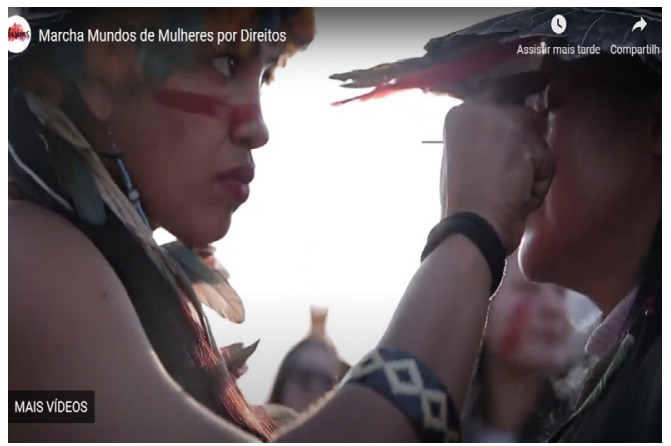

Fonte: Portal Catarinas (2017)

Imagem 4 - Captura de tela do vídeo 1

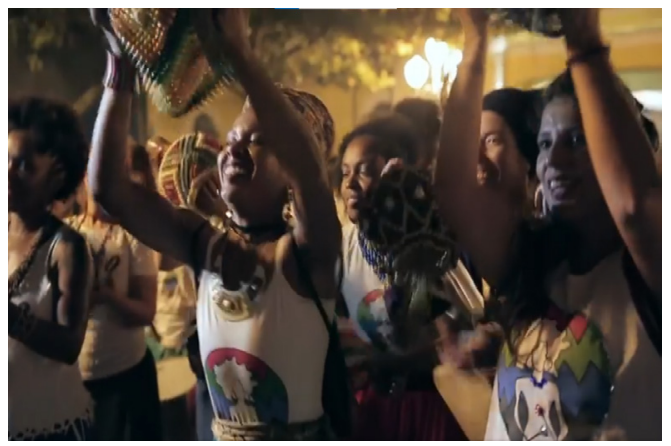

Fonte: Portal Catarinas (2017)

Imagem 5 - Captura de tela do vídeo 1

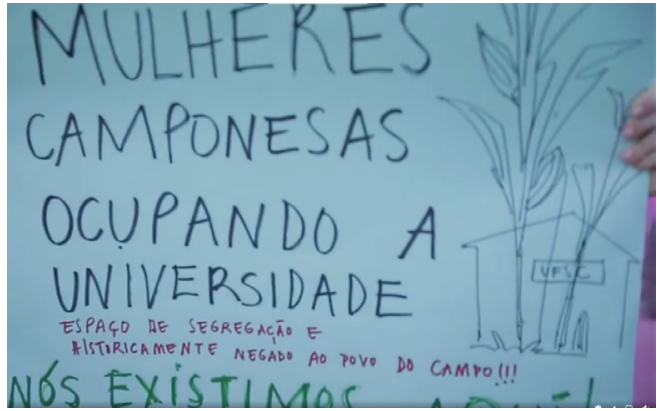

Fonte: Portal Catarinas (2017)

Imagem 6 - Captura de tela do vídeo 1

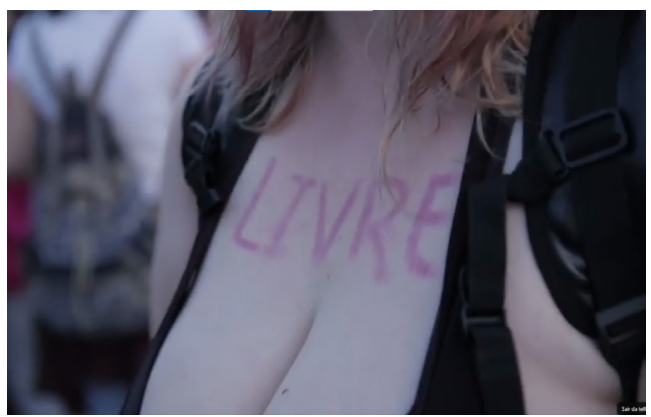

Fonte: Portal Catarinas (2017) 
A música se encerra e voltamos a acompanhar a marcha de mulheres que gritam juntas ao fundo "Nenhuma a menos". Após a câmera registrar mais algumas frases e expressões proferidas em coro, o vídeo começa a mostrar separadamente pedaços da manifestação, dando destaque a falas específicas de diferentes mulheres durante o ato, adotando a linguagem de documentário. Trata-se de falas rápidas, entre bordões, trechos de música ou falas fortes, com legendas nomeando e localizando as entrevistadas. Algumas imagens se intercalam às falas, como a do cartaz "Todo camburão tem um pouco de navio negreiro" ou de um grupo exibindo nos corpos a frase "Demarcação já". Dentre os depoimentos filmados, uma estudante do Paraná brada "Te cuida, te cuida, te cuida seu machista, a América Latina vai ser toda feminista!"; uma professora da Bahia fala de uma ativista lésbica assassinada; uma ativista do Distrito Federal canta uma "marchicha" chamada "Revolução das sapatão"; uma ativista de Porto Alegre diz que "as putas estão unidas". A diversidade de falas e depoimentos segue por essa linha, até as imagens finais, em que são exibidos os créditos ao lado de quadros apontando imagens alternadas de um grupo de mulheres durante $o$ ato, em coro recitando $o$ canto de capoeira "Aidê negra africana", que narra a história de uma mulher negra escravizada que se recusa a casar com o sinhozinho e encontra a liberdade fugindo para um quilombo.

A mistura de bandeiras e povos, unindo corpos contra as forças hegemônicas e heteronormativas vinculadas ao capital e a nossas heranças coloniais traz as imagens para um cosmos coletivo (hooks) de resistência e atuação política. Na relação com a temporalidade, com os espaços e corpos que a câmera percorre no vídeo, sempre colocados em oposição ao poder, estas existências também são carregadas para o lócus fraturado de que fala Lugones. Em movimento constante, as mulheres encaram a câmera, olham no olho de quem está em casa, de quem não foi às ruas num primeiro momento. Evocam afetos. As bandeiras diversas em algum lugar movimentam relações empáticas, provocadas, por exemplo, por cartazes e falas que homenageiam mulheres vítimas do machismo e da violência de gênero. Ao mesmo tempo, pautas vinculadas às desigualdades de gênero, raça e classe se mesclam à luta pela terra, pelo respeito às religiões professadas, ao direito ao aborto, entre outras. Professoras, ativistas, putas, estudantes, jovens, velhas, negras, brancas, indígenas caminham lado a lado e em seguida são destacadas separadamente pela câmera, mas de forma encadeada, ganhando voz. Esse percurso interseccional pode se afirmar no horizonte como uma potencial 
estratégia para romper resistências contemporâneas aos movimentos feministas, efeito da ascensão de movimentos conservadores.

Destacando uma parte da música de abertura, em conjugação com a profusão de imagens descritas acima, observamos uma articulação política que pode ser aproximada do conceito de amefricanidade de Gonzalez, bem como da proposta de cosmovisão conectada com a ancestralidade em bell hooks.

Índia, ó índia [...] Da terra tomada como eu. Dos filhos tirados como os meus. Dos sonhos roubados lá vou eu. [...] Me cobre com tuas ervas sagradas. [...] Me ilumina na mata fechada. [...] Vem comigo, vem sem pressa. Índia negra, negra índia presa. Um encontro de grandezas. Na paz dos povos somos um. Um por todos, todos por um.

Nessa voz que rompe a supremacia branca e heteronormativa, as mulheres nas telas assumem esse lugar. Ao mesmo tempo, o encerramento com um coro de mulheres recitando uma história que remete à chegada de uma mulher negra escravizada ao quilombo, expressão da liberdade, resgata a potência dessa ancestralidade, e faz com que todos os corpos em cena abarquem essa estratégia de luta com dimensão não colonizada para si. A opressão, a violência, o sexismo são todos colocados, portanto, como efeitos da colonização passíveis de serem enfrentados nos múltiplos devires de mulher que percorrem a manifestação. Relembrando que em seu trabalho Lélia Gonzalez valoriza também, como potência a ser resgatada, saberes muitas vezes relegados a uma inferioridade, como a música, a ginga, a oralidade e os afetos advindos da África. A exposição reiterada dos diversos corpos femininos dançando, cantando e performando, ao som da música exposta, portanto, evoca esta potência política.

\subsection{Vídeo 2 - Convocatório para Huelga Mundial Feminista, Coordina- dora 8M, Chile, 2021}

Com duração de 1min 1s, este vídeo tinha o intuito de convocar participantes para as manifestações que tomaram as ruas do Chile no dia 08 de março de 2021, durante a greve mundial feminista. A peça traz um jingle composto especificamente para este propósito, em ritmo de reggaetón latino. Filmado já durante a pandemia da Covid-19, traz uma combinação de performances produzidas e encenadas para o vídeo, junto com imagens de arquivo das manifestações anterio- 
res. O vídeo se abre com a imagem de uma mulher de costas amarrando um lenço roxo no rosto, que remete a imagens cinematográficas de pessoas se preparando para uma batalha, enquanto a voz da cantora anuncia, como o ritmo ao fundo: "Se vien la huelga general femenista. Agarra tus hermanas e tus abuelas y nos vamos pa la calle" ${ }^{\prime \prime}$. Em seguida, vemos em primeiro plano cenas alternadas dos rostos de jovens cobertos por lenços com símbolos da luta feminista, encarando a câmera/ espectadora. Após as imagens dos rostos femininos, seguem cenas da manifestação de 2020 e de algumas anteriores, numa montagem dinâmica que alterna as imagens da multidão com as das danças, faixas, cartazes e performances na rua. Quando começa o refrão do jingle, vemos imagens em plano de conjunto de um grupo de jovens com lenços nos rostos dançando sensualmente uma coreografia, ao ritmo da música. As imagens de algumas performances passam a ser alternadas com as de registros durante as manifestações, de acordo com a letra da música, exibida nas legendas.

A partir da análise das imagens e da letra do jingle fica evidente se tratar de um material mais direcionado para o público jovem feminino. Além do uso de gírias e linguagem das redes sociais, destacamos também alguns termos e expressões que remetem ao "universo feminino", como "Vamoh acicala", traduzindo: Vamos nos arrumar. A frase é proferida logo após a exibição dos rostos com lenços que exibem maquiagem colorida nos olhos, e exatamente no momento em que surge uma imagem de arquivo com jovens dançando durante uma manifestação anterior.

\section{Imagem 7 - Captura de tela do vídeo 2}

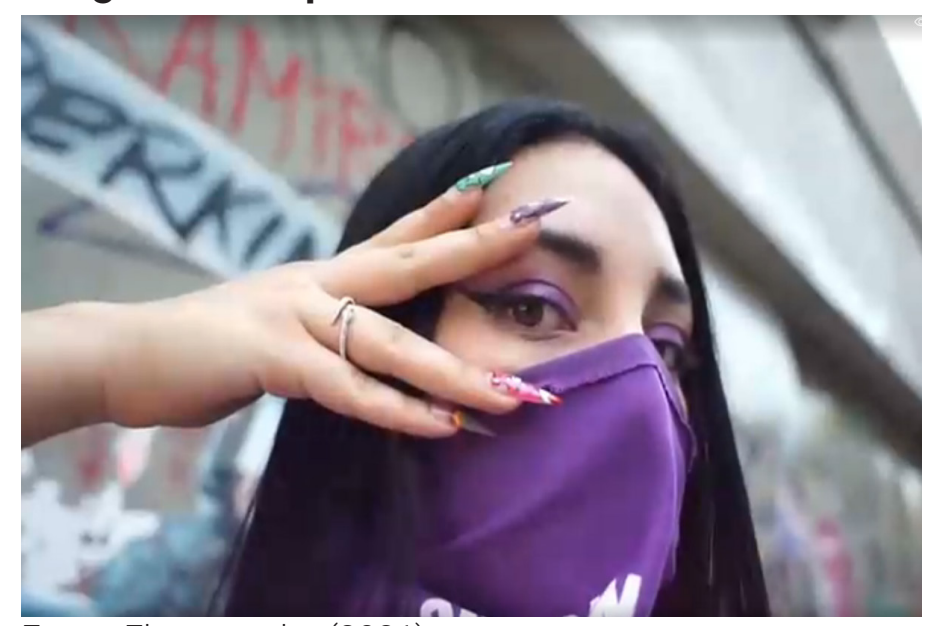

Fonte: El mostrador (2021)

\footnotetext{
6 "Vem aí a greve geral feminista. Pegue suas irmãs e avós e vamos para a rua" (tradução nossa).
} 


\section{Imagem 8 - Captura de tela do vídeo 2}

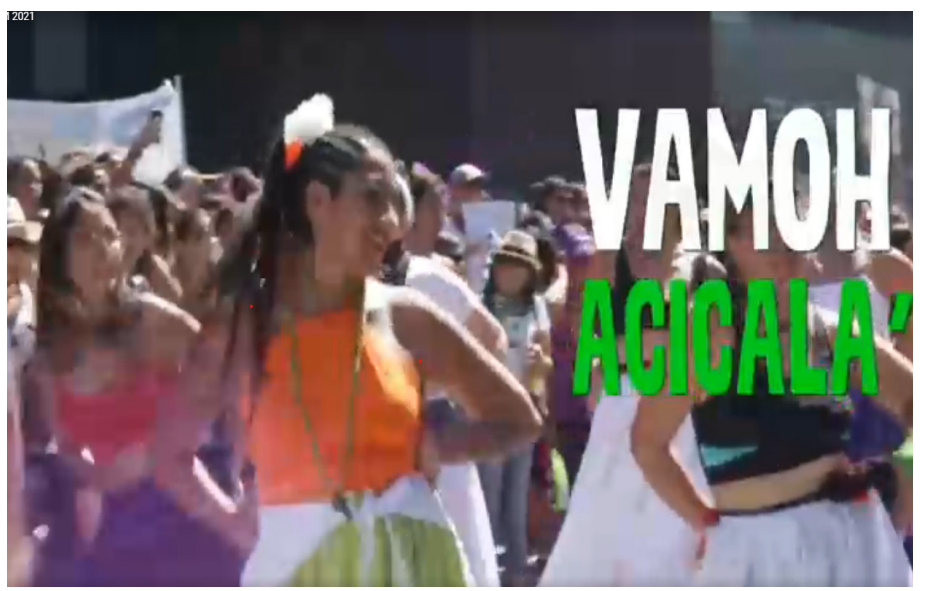

Fonte: El mostrador (2021)

Podemos retomar aqui o conceito de diferença sexual estabelecido por Rosi Braidotti, em que proclama as repetições como forma de contramemória (2015). Neste processo de revisitar lugares essencializados e construídos por forças hegemônicas, podemos reelaborar seus significados e estrategicamente subvertê-los. Observamos que as personagens femininas se tornam donas da ação nestes vídeos, tanto pelos espaços que ocupam nas telas, como por meio do olhar reproduzido nas sequências e dos movimentos conjugados às falas na edição, cujo conteúdo é meticulosamente articulado com as imagens em que são exibidas.

Observamos também que a exposição de forma sensual dos corpos femininos é ressaltada, mas em tom de afronta, estabelecendo um lócus fraturado numa estrutura política de dominação fundamentada numa sociedade capitalista e violenta. O conservadorismo chileno, marcado por 27 anos de ditadura militar (1973-1990) e a ascensão de governos de direita e essencialmente masculinos, é desafiado pelas bundas que balançam quando a letra da música se refere ao detentor de poder: "Pagan essos que se creen dueños de nuestro trabalho" e "Essos que viven lucrando con direitos sociales". Ambas as frases vêm acompanhadas de imagens de corpos femininos sacudindo as bundas. A segunda, inclusive, surge sobre a imagem de uma mulher plantando bananeira (imagem 10), ou seja, literalmente invertendo a ordem de opressão, como vemos nos fotogramas ilustrativos: 


\section{Imagem 9 - Captura de tela do vídeo 2}

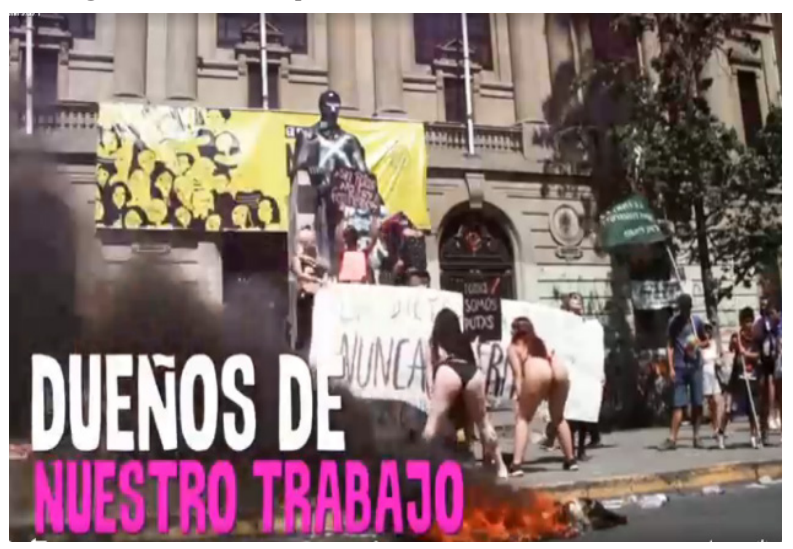

Fonte: El mostrador (2021)

\section{Imagem 10 - Captura de tela do vídeo 2}

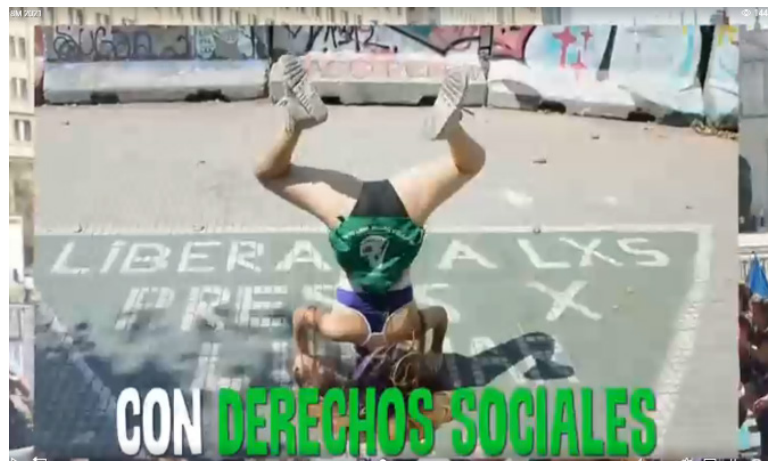

Fonte: El mostrador (2021)

Destacamos também o uso do pronome indicativo no masculino "essos" ("esses", em português) para se referir aos que lucram com a força de trabalho, indicando se tratar de uma força masculina, contra a qual o movimento luta. Ao final do clipe reforça-se ainda a transgressão ao poder masculino: "Sen los pacos ${ }^{7}$ y sen Piñero ${ }^{8}$, este 8 vamos a vencer". A narrativa afasta-se, desta forma, de uma lógica binária de oposição, recorrente no pensamento feminista das primeiras décadas do século XX e criticado pela perspectiva pós-estruturalista aqui contemplada (SCOTT, 2018), visto que o "sen" remete a uma força não reconhecida, a uma luta que se constrói "sem eles" e com nossos corpos. E, desta forma, vamos vencer.

Destacamos também o uso de letterings e legendas ao longo da peça, não apenas com a função de demarcar o chamado, mas também de ressignificar a própria função das legendas. A utilização de legendas e letterings em matérias jornalísticas e peças publicitárias audiovisuais é observado por Souza (2000) a partir da perspectiva francesa da Análise do Discurso (AD). A autora reitera, via uma aná-

\footnotetext{
7 "Sem os policiais" (tradução nossa).

8 "E sem Piñero" (tradução nossa). Sendo Piñero o presidente chileno.
} 
lise de imagens recorrentes na mídia tradicional, a função deste recurso "escrito" em provocar um "direcionamento de sentidos" das imagens, que acaba conduzindo e restringindo o processo de interpretação, considerado pela AD um processo de interlocução entre sujeitos em diferentes posições. No caso desse vídeo, essa função se vê subvertida, na medida em que a combinação da montagem com as imagens expostas e os trechos destacados quadro a quadro ampliam a rede de significados das imagens com frases como "Greve, porque não podem conosco" destacadas do jingle que acompanha o vídeo chileno.

\section{Imagem 12 - Captura de tela do vídeo 2}

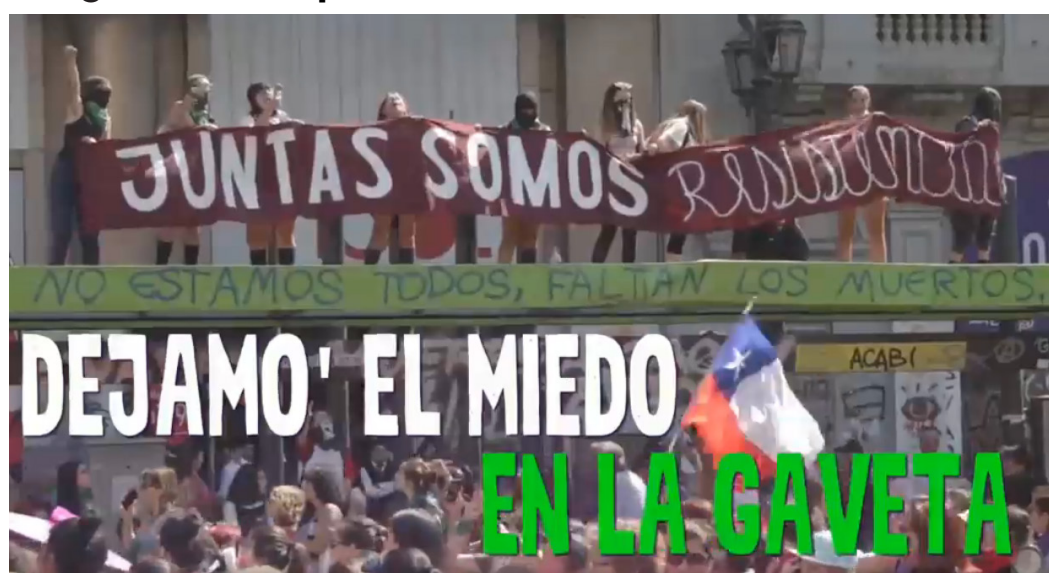

Fonte: El mostrador (2021)

Dessa forma, frases como "Deixamos o medo na gaveta"10 (imagem 12), por exemplo, permitem explorar uma série de significados, como a expressão "sair do armário", referente à assunção da homossexualidade. Essa frase evoca outras lutas políticas, como a LGBTQIA+, associando-as à causa feminista. 0 medo pode se referir também ao momento que passam, durante a pandemia, bem como ao histórico recente à convocação, de repressão violenta dos atos contra a crise chilena ocorrida em 2019. Ressaltamos também o fato de a violência de gênero ter sido tema de diversas manifestações latino-americanas nos últimos anos. Tornou-se célebre, por exemplo, a performance chilena "O estuprador é você", criada pelo coletivo Las Tesis em 2019, ganhando voz e performances em manifestações feministas mundo afora. Essa performance foi apresentada pela primeira vez nas ruas de Valparaíso como parte dos manifestos contra a violência que precederam o dia 25 de novembro, o dia internacional de combate à violência contra a mulher.

\footnotetext{
9 Tradução nossa.

10 Tradução nossa.
} 


\section{Imagem 13 - Captura de tela do vídeo 2}

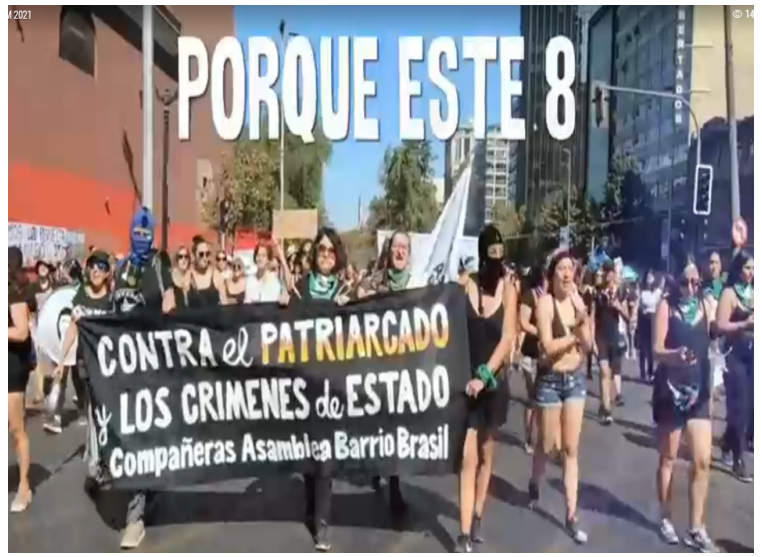

Fonte: El mostrador (2021)

\section{Imagem 14 - Captura de tela do vídeo 2}

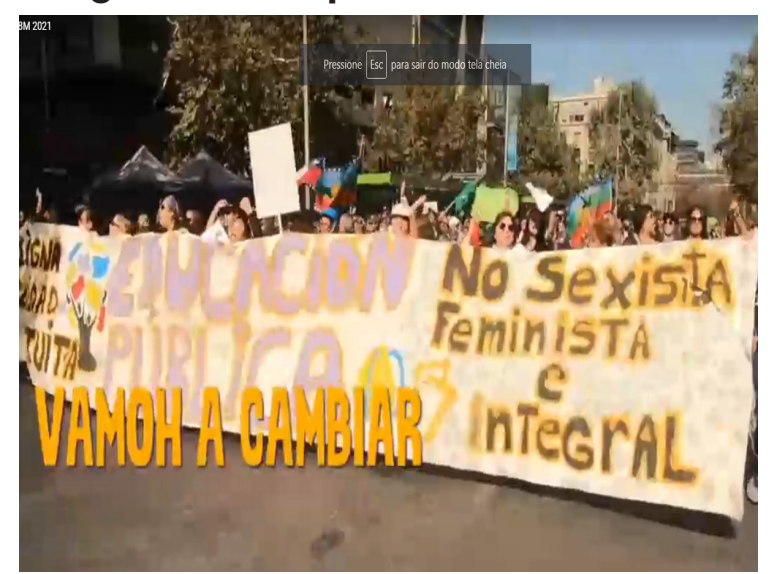

Fonte: El mostrador (2021)

\section{Considerações finais}

Traçando um olhar comparativo e combinado entre os dois vídeos analisados, constatamos que ambos optaram pela articulação de influências de diferentes formatos que se entrecruzam - arte contemporânea, narrativa jornalística, documentário, canto, poesia e performance etc. -, para a construir um formato narrativo próprio, com foco nas questões de gênero e suas intersecções. Na análise que contemplou elementos estéticos e discursivos dos vídeos, identificamos também que ambos escolheram se posicionar politicamente a partir das perspectivas teóricas e políticas contemporâneas elencadas: a abordagem de concepções de representação e subjetividades caras à perspectiva pós-estruturalista, mas, a exemplo da proposta de Nancy Fraser, com foco na transformação. Ou seja, lançam mão de um jogo que articula a afırmação da vulnerabilidade feminina, com a força de corpos que se deslocam e ganham poder na própria capacidade de não 
se fixarem. O eixo principal de articulação reside na valorização do pensamento feminista decolonial e das pautas feministas interseccionais.

A relevância dos movimentos políticos a partir dos anos 2000 levou Judith Butler a se dedicar ao tema em Corpos em aliança e a política nas ruas, agora pensando no contexto da eclosão das manifestações de rua e das reivindicações sobre as questões de gênero mais contemporâneas. Retomando a performatividade de gênero e a representação nesse contexto, a autora afirma que "não são apenas o gênero e a sexualidade que são performativos, mas também suas articulações políticas e as reivindicações feitas em seu nome” (2017, p. 64). Assim, o ato performativo também é visto como uma forma de agir contra a precariedade que envolve os que não tem direitos. Ao mesmo tempo, temos que considerar, no caso das mulheres latino-americanas, que as próprias normas de reconhecimento que garantem a nossa existência, como é o caso da sacralização da maternidade, também podem colocar em risco a nossa sobrevivência. Isso deixa evidente também como a própria vulnerabilidade pode fazer eclodir ressignificações e rupturas. E não é à toa que as manifestações feministas entram em evidência no exato momento em que os corpos femininos se veem ameaçados e em situação de precariedade. É nesse momento também que outros corpos em situação de precariedade, como os LGBTQIA+s e as minorias sociais e raciais, se agregam à luta das mulheres e vice-versa.

Antes de finalizarmos este texto, é fundamental reiterarmos que as articulações que assistimos hoje nas ruas são mérito da inserção de outras lutas dentro do espectro do feminismo. No caso brasileiro e de outras nações com histórico de escravidão, sobretudo as conquistas dos coletivos de mulheres negras e indígenas, entre outros movimentos e lutas de minorias sociais e espaciais. Sueli Carneiro já afirmava em 2003 que "o protagonismo de mulheres negras tem se constituído em força motriz para determinar as mudanças nas concepções e reposicionamento político feminista no Brasil." (2003, p. 8) Da mesma forma, as lutas de mulheres indígenas e a eclosão dos movimentos de mulheres de povos originários na América Latina como um todo, na luta pela terra, pelo direito à vida, contra o patriarcado, pelo fim das desigualdades econômicas, da violência física e simbólica, alimentaram e construíram as bases para os movimentos que vemos eclodir nas ruas. Neste sentido, tomamos aqui emprestadas as palavras de bell hooks, procurando estendê-las para as causas levantadas nas manifestações e vídeos de registro e disseminação: 
Para aqueles que ousam desejar de modo diferente, que procuram desviar o olhar das formas convencionais de ver a negritude e nossas identidades, a questão da raça e da representação não se restringe apenas a criticar o status quo. É também uma questão de transformar as imagens, ciar alternativas, questionar quais tipos de imagens subverter, apresentar alternativas críticas e transformar nossas visões de mundo e nos afastar de pensamento dualistas acerca do bom e do mau (HOOKS, 2019, p. 32).

Outra característica dos manifestos contemporâneos que se vê refletida nos vídeos analisados é a afırmação e exposição da diversidade de reivindicações e de corpos colocados em cena. Há um ponto que difere um pouco os dois vídeos em questão, que se refere ao fato de o vídeo brasileiro tematizar a luta mais abrangente das mulheres, e se configurar um registro de um encontro feminista internacional sediado numa cidade brasileira. O vídeo chileno se tratava de uma convocação, uma peça que visava atrair o público. Ante a crise econômica no Chile, reivindicava também pautas um pouco mais específicas, no caso, convocava uma greve feminina contra as desigualdades econômicas e o patriarcalismo. Assim, destacam-se mais cenas, cores e diferentes bandeiras no vídeo brasileiro, mas o que observamos é que o outro vídeo também se esforça por exibir mulheres de diferentes faixas etárias e raças, bem como as diferentes bandeiras expostas nos atos. As diferenças estéticas observadas provavelmente se devem a escolhas referentes aos estilos de trabalho dos coletivos de criação. No caso do vídeo brasileiro, se trata de um portal de jornalismo com enfoque feminista. No caso chileno o coletivo feminista organizador dos movimentos de 8 de março no país. Entre a convocação chilena que procura atrair jovens para as ruas com uma peça divertida e envolvente, e a celebração brasileira com tom mais jornalístico, encontramos pontos de convergência na abordagem política e teórica das causas observada anteriormente. As técnicas de montagem utilizadas trabalham nesse sentido, não apenas dinamizando as narrativas, mas privilegiando as intersecções que se encontram em pautas coletivas, como a legalização do aborto, o fim da violência de gênero, do racismo, da homofobia, entre outras. Ambos se conectam como efeitos do mesmo patriarcalismo que gerou a crise chilena e, no caso brasileiro, na época recente o processo de impeachment da presidente Dilma Rousseff (traduzimos como golpe), que antecedeu e reacendeu os protestos expostos no vídeo brasileiro de 2017. 
Por fim, encerramos as análises e articulações propostas reiterando a potência do audiovisual e da utilização destes materiais, principalmente se considerarmos o contexto atual, em que os contatos com as telas se intensificaram a partir da eclosão da pandemia de Covid-19. Aos poucos, as questões proeminentes têm nos levado de volta às ruas, com os devidos cuidados. Vide as reivindicações argentinas que atravessaram o período e se concretizaram em dezembro de 2020, com a conquista da legalização do aborto, já em meio à pandemia, levando milhares de mulheres às ruas, gerando novos registros circulantes e proliferados mundo afora. Assim, os movimentos e manifestos de mulheres nas ruas na América Latina, geram novos registros, sucessivamente proliferados e disseminados. Ruas, corpos e telas, desta forma, se retroalimentam.

\section{Referências}

BRAIDOTTI, Rosi. Affirming the affirmative: on nomadic affectivity. Rhizomes, Bowling Green, Bowling Green State University, n. 11, 2005/2006. Disponível em: http://www.rhizomes.net/issue11/braidotti.html. Acesso em: 12 ago. 2011.

Nomadic subjects: embodiment and sexual difference in contemporary feminist theory. New York: Columbia University press, 1994.

Feminismo, diferencia sexual y subjetividad nómade. Barcelona: Editorial Gedisa, 2015.

BUTLER, Judith. Problemas de gênero: feminismo e subversão da identidade. 7. ed. Rio de Janeiro: Civilização Brasileira, 2003.

Corpos em aliança e a política das ruas: Notas sobre uma teoria performativa de assembleia. Rio de Janeiro: Civilização Brasileira, 2018.

COORDINADORA Feminista 8M lanza video sobre la huelga feminista en la previa de la conmemoración del Día de la Mujer. Produção do Coletivo Coordinadora 8M. 1 min e 16 segs, son., color. El mostrador, 2021. Disponível em: https://www. elmostrador.cl/braga/2021/03/04/coordinadora-8m-lanza-video-sobre-la-huelgafeminista-en-la-previa-de-la-conmemoracion-del-dia-de-la-mujer/. Acesso em: 24 maio 2021.

CRENSHAW, Kemberlé. Documento o encontro de especialistas em aspectos da discriminação racial relativos ao gênero. Revista Estudos Feministas, v. 10, n. 1, p. 171-188, 2002. Disponível em: https://www.scielo.br/j/ref/a/ mbTpP4SFXPnJZ397j8fSBQQ/?format=pdf\&lang=pt. Acesso em: 12 jun. 2021.

DAVIS, Angela. Mulheres, raça e classe. São Paulo: Boitempo, 2016. 
ESCOSTEGUY, Ana Carolina D. Comunicação e gênero no Brasil: discutindo a relação. Revista Eco-Pós, Rio de Janeiro, Universidade Federal do Rio de Janeiro, v. 23, n. 3, 2020. Disponível em: https://revistaecopos.eco.ufrj.br/eco_pos/article/ view/27643/pdf. Acesso em: 18 abr. 2021.

FRASER, Nancy. Da redistribuição ao reconhecimento? Dilemas da Justiça numa era "pós-socialista". Revista Cadernos de Campo, São Paulo, v. 15, n. 14-15, p. 231-239, 2006.

GONZALEZ, Lélia. A categoria político-cultural da amefricanidade. Revista Tempo Brasileiro, n. 92-93, p. 69-82, 1998.

A mulher negra na sociedade brasileira: uma abordagem políticoeconômica. In: RODRIGUES, Carla, BORGES, Luciana e RAMOS, Tania R. O. (Org.). Problemas de gênero. Coleção Ensaios Brasileiros Contemporâneos. Vol. 3. Rio de Janeiro: Funarte, 2016.

GONZALEZ, Mariana. Quarta onda do feminismo é tipicamente latino-americana, diz fundadora do Ni Una Menos. Revista Cult, 2017. Disponível em: https:// revistacult.uol.com.br/home/quarta-onda-feminismo-latino-americana/. Acesso em: 18 abr. 2021.

HALL, Stuart. Da diáspora: identidades e mediações culturais. Belo Horizonte: Editora UFMG, 2011.

Que negro é esse na Cultura negra? In: HALL, Stuart. Da diáspora: identidades e mediações culturais. Belo Horizonte: Editora UFMG, 2011.

Cultura e representação. Rio de Janeiro: Editora PUC-Rio; Apicuri, 2016.

HERMANAS. Produção de Emergentes e Mátria. 1 min e 36 seg, son, color. Facebook Hermanas, 2018. Disponível em: https://www.facebook.com/ watch/?v=623681574662290. Acesso em: 20 fev. 2020.

HOLLANDA, Heloísa Buarque et al. Explosão feminista: arte, cultura, política e universidade. São Paulo: Companhia das Letras, 2018.

Pensamento Feminista: conceitos fundamentais. São Paulo:

Companhia das Letras, 2018.

HOOKS, bell. Olhares Negros: raça e representação. São Paulo: Elefante, 2019.

LUGONES, María. Rumo a um feminismo descolonial. Revista Estudos

Feministas, Florianópolis, v. 22, n. 3, 2014.

MARCHA mundo de mulheres por direitos. 4 min e 26 seg., son., color. Portal de Catarinas, 2017. Disponível em: https://www.youtube.com/watch?v=cTIA1j9RjPE. Acesso em: 16 mar. 2018. 
MARTÍN-BARBERO, Jesús. Dos meios às mediações: comunicação, cultura e hegemonia. 7. ed. Rio de Janeiro: Editora UFRJ, 2015.

RATTS, Alex; RIOS, Flávia. A perspectiva interseccional de Lélia Gonzalez. In: Lélia Gonzalez: retratos do Brasil negro. 1. ed. São Paulo: Selo Negro, 2010.

SCOTT, Joan. Gênero, uma categoria útil para análise histórica. In: HOLLANDA, Heloísa Buarque et al. Pensamento Feminista: conceitos fundamentais. São Paulo: Companhia das Letras, 2018.

SODRÉ. Muniz. Sobre Imprensa Negra. Lumina, Juiz de Fora, Universidade Federal de Juiz de Fora, v. 1, n. 1, p. 23-32, 1998.

Pensar Nagô. Petrópolis: Editora Vozes, 2017.

SOUZA, Tânia Conceição Clemente de. A análise do não verbal e os usos da imagem nos meios de comunicação. Revista Rua, Campinas, v. 7, n. 1, p. 65-94, 2015. 